\title{
LEGITIMAÇÃO, GERENCIAMENTO DE IMPRESSÕES E ENQUADRAMENTO NA RELAÇÃO ORGANIZAÇÃO-STAKEHOLDER: UM ENSAIO TEÓRICO
}

\section{LEGITIMACY, IMPRESSION MANAGEMENT FRAMEWORK AND FRAMING IN THE ORGANIZATION-STAKEHOLDER RELATIONSHIP: A THEORETICAL ESSAY}

\section{José Ricardo Costa de Mendonça}

Doutor em Administração pela Universidade Federal do Rio Grande do Sul (UFRGS). Professor do Programa de Pós-Graduação em Administração (PROPAD) da Universidade Federal de Pernambuco (UFPE). E-mail: jrcm@ufpe.br (Brasil)

\section{Diogo Henrique Helal}

Doutor em Ciências Humanas, com concentração em Sociologia, pela Universidade Federal de Minas Gerais (UFMG). Professor da Fundação Joaquim Nabuco - FUNDAJ - MEC e Faculdade Boa Viagem - FBV - Adtalem. E-mail: diogohh@yahoo.com.br (Brasil) 


\title{
LEGITIMAÇÃO, GERENCIAMENTO DE IMPRESSÕES E ENQUADRAMENTO NA RELAÇÃO ORGANIZAÇÃO-STAKEHOLDER: UM ENSAIO TEÓRICO
}

\section{RESUMO}

O ensaio teórico discute como os gestores de alto escalão buscam influenciar as interpretações das audiências em busca de legitimidade para as organizações. Argumenta-se que os gestores de alto escalão ao se relacionarem com os stakeholders engajam-se em processos de gerenciamento de impressões visando enquadrar as percepções e interpretações das audiências organizacionais à visão de realidade mais propícia a criação da imagem e da reputação que levem à obtenção da legitimidade da organização em seu ambiente social. A atividade de enquadrar envolve selecionar alguns aspectos de uma realidade percebida e torná-los mais salientes em uma comunicação, de tal modo a promover uma determinada definição de um problema, uma interpretação causal, uma avaliação moral e/ou recomendações de tratamento para o assunto descrito. Com base em revisão de literatura, o artigo propõe uma versão expandida do modelo de Mendonça e Amantino-de-Andrade (2003), sobre o processo de legitimação por meio do uso do gerenciamento de impressões organizacional, incorporando o processo de framing e a reputação organizacional.

Palavras-chave: Enquadramento. Gerenciamento de impressões organizacional. Relação Organização-Stakeholder. Processo de legitimação. Ensaio teórico.

\section{LEGITIMACY, IMPRESSION MANAGEMENT FRAMEWORK AND FRAMING IN THE ORGANIZATION-STAKEHOLDER RELATIONSHIP: A THEORETICAL ESSAY}

\begin{abstract}
The article discusses how top managers seek to influence the interpretations of the audience in search of legitimacy for organizations. It is argued that senior managers to relate to stakeholders engage in impression management processes in order to frame perceptions and interpretations of organizational audiences to a more favorable view of reality to create the image and the reputation that lead to obtaining the organization's legitimacy in their social environment. The activity of framing involves selecting some aspects of a perceived reality and make them more salient in communication, such as to promote a particular definition of a problem, a causal interpretation, moral evaluation and / or treatment recommendations for the subject described. Based on literature review, we propose an expanded version of the Mendonça and Amantino-of-Andrade model (2003), which incorporates the framing process and organizational reputation.
\end{abstract}

Keywords: Framing. Organizational impression management. Organization-Stakeholder relation. Process of legitimacy. Theoretical model. 


\section{INTRODUÇÃO}

$\mathrm{O}$ estudo dos fenômenos organizacionais tem se consolidado como uma área de grande interesse e importância em diversas disciplinas cientificas. Uma das abordagens adotadas por pesquisadores para os estudos das organizações é a perspectiva institucional. Tal perspectiva pode ser tipificada como uma abordagem simbólico-interpretativa da realidade organizacional, que apresenta uma posição epistemológica predominantemente subjetivista e salienta a construção social da realidade organizacional. Apesar de o foco deste trabalho não aprofundar a discussão sobre a teoria institucional, cabe destacar que este texto é influenciado pela perspectiva institucional, especificamente pelas ideias do novo institucionalis mo.

No novo institucionalismo, destacam-se as relações entre a organização e seu ambiente e valoriza-se o papel da cultura na formação da organização. Entende-se o ambiente como sendo formado pelo ambiente técnico e pelo ambiente institucional. Sob a perspectiva institucional, as organizações concorrem pela legitimidade e pela aceitação em seus ambientes. Legitimidade pode ser entendida como uma percepção generalizada de que as ações da organização são desejadas, corretas e apropriadas dentro do sistema de normas, valores e crenças do ambiente (Suchman, 1995).

Hooghiemstra (2000), ao discutir a divulgação e a exposição de comportamentos ambientais e sociais de organizações, chama a atenção para o fato de a teoria da legitimidade ser o modelo mais amplamente usado para explicar esses processos de comunicação. Um aspecto central para a teoria da legitimidade é o conceito de "contrato social", o qual sugere que a sobrevivência de uma organização vai depender da sua capacidade de operar dentro dos limites e das normas definidas pela sociedade. Porém, cabe destacar que o status de legitimidade não é permanente e os critérios para a sua obtenção não são imutáveis.

Não se pretende aqui explorar a teoria da legitimidade ou o conceito de contrato social, mas sim chamar a atenção para a ideia subjacente da necessidade de a organização comunicar (expor) suas ações com o objetivo de demonstrar as suas audiências (stakeholders) que ela cumpre as normas societais e, assim, obter legitimidade. Entende-se por stakeholder qualquer grupo ou indivíduo que pode afetar ou ser afetado pela realização dos objetivos dessa empresa (Freeman, 1984). Outra definição operacional é apresentada por Savage, Nix, Whitehead e Blair (1991). Para os autores, stakeholder inclui aqueles indivíduos, grupos e outras organizações que têm interesse nas ações de uma empresa e que têm habilidade para influenciá- la. 
Mendonça e Amantino-de-Andrade (2002, 2003) buscando contribuir com novos insights sobre um ponto que representa uma das principais críticas dirigidas ao institucionalismo - a sua limitada capacidade em explicar adequadamente a ação e a mudança - propõem um modelo que integra a teoria institucional e as teorias de gerenciamento de impressões (GI) e procura explicar como as organizações buscam criar imagens que thes proporcionam legitimação no ambiente social. Com o pressuposto de que a realidade organizacional é socialmente construída e institucionalmente sustentada, os autores defendem que as teorias de GI associadas aos aportes teóricos do campo da comunicação corporativa e dos estudos organizacionais, podem auxiliar e enriquecer o entendimento sobre os processos por meio do quais as organizações obtêm legitimidade em seus ambientes.

O gerenciamento de impressões é, basicamente, o processo por meio do qual as pessoas buscam controlar ou influenciar as impressões que outros formam a seu respeito (Giacalone \& Rosenfeld, 1989). Sob esta perspectiva assume-se que as pessoas se engajem em comportamentos de gerenciamento de impressões de maneira a propiciar a realização de seus objetivos e metas, tanto individualmente quanto como membros de grupos e organizações.

Carter (2006, p. 1146) chama a atenção para o fato de que "pesquisadores da psicologia e da psicologia social dedicaram décadas explorando o gerenciamento de impressões e têm ajudado a compreender como, quando e que tipos de atividades os indivíduos podem provavelmente usar para gerenciar suas próprias reputações”. Não apenas os indivíduos, mas também as organizações podem tentar influenciar a percepção das pessoas por meio do uso de dispositivos de gerenciamento de impressões (Hooghiemstra, 2000). Clientes, gerentes, empregados, outras organizações, todos fazem parte de uma teia de relações onde afetar as impressões de outros atores sociais sobre si mesmo faz parte do jogo; sendo assim, o gerenciamento de impressões pode ser considerado uma parte significativa da vida organizacional (Mendonça \& Fachin, 2001).

Apesar de muitos pesquisadores terem investigado o GI no nível individual de análise, buscando entender os modos pelos quais os comportamentos de "atores" afetam a avaliação feita pelos "alvos" (Bolino, Kacmar, Turnley \& Gilstrap, 2008), há alguns anos as teorias de gerenciamento de impressão foram adaptadas para o nível organizacional de análise (Mohamed, Gardner \& Paolillo, 1999).

Acredita-se que no processo de busca da legitimidade, as organizações, como atores sociais, são representadas (ou personificadas) por seus gestores, os quais tomam decisões e 
agem em nome da organização. Os gestores de alto escalão (top managers) são um determinante-chave das decisões estratégicas e dos resultados organizacionais (Carter, 2006).

Gestores de alto escalão podem ser definidos como o indivíduo ou indivíduos para quem as audiências da organização se voltam no sentido de obter informações que ajudem em suas interpretações de um evento ou situação com a qual a organização esteja relacionada. Eles representam uma parte primordial no processo de legitimação, exercendo múltiplos papéis na organização.

Os papéis são conjuntos predeterminados de comportamentos, tarefas e ações que se espera que alguém desempenhe. No que se refere aos papéis gerenciais, Mintzberg (1973) identificou dez papéis comuns ao trabalho de todos os gerentes: interpessoal - figura principal, líder e ligação; informacional - monitor, disseminador e porta-voz; e decisório empreendedor, administrador de problemas, alocador de recursos e negociador.

Observa-se nos papéis gerenciais de Mintzberg (1973) que os gestores, em linhas gerais, representam a organização (internamente e externamente), mantêm a ligação entre a organização e suas audiências, controlam o fluxo de informações-chave, buscam solucionar problemas ou neutralizar ameaças à organização e atuam como negociadores em nome da organização. Argumenta-se que essas características do papel do gestor corroboram a importância e a escolha do foco na ação gerencial neste trabalho.

Ao construir relacionamentos com empregados, clientes e outros públicos de interesse, significados, conexões e mutualidades são criadas por intermédio da construção da linguagem relacionada aos vários discursos organizacionais.

Smircich e Morgan (1982, 1997), ao discutirem a liderança como um processo de gerenciamento de significados, defendem que as ações dos indivíduos, por diversos meios, podem moldar (enquadrar) e mudar situações. Assim ordenando um sistema de significados compartilhados que proveem uma base para a ação organizada.

Percebe-se que um desafio importante para os gestores nas organizações, é gerenciar os significados de tal modo que estes orientem a realização dos fins desejáveis. Para tanto, os gestores usam a linguagem, os rituais, o drama, as estórias, os mitos e vários tipos de construções simbólicas como ferramentas (Smircich \& Morgan, 1982).

Pesquisas sobre mudança institucional têm enfatizado o papel de relatos legitimadores e da retórica como meios pelos quais atores sociais (individuais e coalizões) reforçam suas posições. Os atores sociais no sentido de fazer com que os seus próprios frames predominem, empreendem esforços para estabelecer a legitimidade dos frames em si e para validar a sua própria autoridade como reivindicantes (Kaplan, 2008). 
O framing pode ser entendido como o processo pelo qual o ator gerencia significados e constrói socialmente a realidade para si mesmo e para outros (Fairhurst \& Sarr, 1996). Os conceitos de framing vêm sendo empregados de várias maneiras para explicar a estruturação das mensagens e as diferentes respostas que podem resultar. Em algumas instâncias, o framing envolve a definição da cena ou situação na qual os indivíduos interagem; em outras, oframing vincula mensagens que se focam seletivamente em atributos-chave de uma causa, candidato, produto ou serviço.

Framing pode também ser empregado para estruturar o modo como indivíduos pensam sobre escolhas e cursos alternativos de ação que eles podem usar para atingir seus objetivos. De forma similar, o framing pode ser usado para definir ações, questões ou problemas sociais. E, finalmente, o framing de notícias é um processo vital usado pela mídia para relacionar eventos de modo que esses tenham relevância e significado para as audiências (Hallahan, 1999).

Levando-se em consideração o exposto acima, este artigo desenvolve-se no sentido de propor um modelo explicativo de como os gestores de alto escalão, no processo de comunicação com os stakeholders, tentam influenciar as interpretações das audiências em busca de legitimidade para as organizações.

Argumenta-se que os gestores de alto escalão ao se relacionarem com os stakeholders engajam-se em processos de gerenciamento de impressões visando enquadrar (framing) as percepções e as interpretações das audiências organizacionais à visão de realidade mais propícia a criação da imagem e da reputação que levem a obtenção da legitimidade da organização em seu ambiente social.

Observa-se na literatura que ainda poucos pesquisadores têm focado os processos de gerenciamento no nível organizacional de análise. Esta lacuna ainda é mais significativa no Brasil onde os estudos sobre GI em administração tiveram início no final da década de 1990. Este trabalho busca trazer não apenas uma contribuição para a discussão e os estudos do GI no nível organizacional, mas também, por meio da união de insights e de teorias que poderiam, caso contrário, permanecer dispersos em outras disciplinas científicas, contribuir para a melhor compreensão dos processos de legitimação das organizações.

Apesar da importância atribuída ao processo de gerenciamento de impressões na literatura de sociologia, de psicologia, de comunicação, de gestão, dentre outras áreas do conhecimento, observa-se uma significativa lacuna na literatura brasileira sobre o tema, 
ocasionada, muito provavelmente, pela ausência de um maior número de estudos que ofereçam informações sobre como se processa este fenômeno na realidade nacional.

No tópico a seguir é apresentado o referencial que oferece a fundamentação para o argumento teórico estruturante na construção do modelo (framework) proposto. Entende-se, neste trabalho, um framework como uma estrutura real ou conceitual, que tem o objetivo de servir como apoio ou guia para a construção ou ampliação do conhecimento científico.

\section{GERENCIAMENTO DE IMPRESSÕES ORGANIZACIONAL}

O gerenciamento de impressões descreve os esforços de um ator para criar, manter proteger ou alterar uma imagem mantida por uma audiência-alvo. $\mathrm{O}$ ator usa, para realizar seu objetivo, uma variedade de táticas de GI (comportamentos específicos) planejadas para criar a imagem desejada (Bolino; Kacmar; Turnley \& Gilstrap, 2008).

Nas últimas décadas, os pesquisadores têm usado pesquisas do nível individual como base para a compreensão das ações dos membros organizacionais e têm também demonstrado que podem prover grande conhecimento sobre quando as atividades de gestão da reputação serão usadas com maior probabilidade no nível organizacional (Carter, 2006).

Bolino, Kacmar, Turnley e Gilstrap (2008) salientam que a maior parte das pesquisas tem sido devotada ao nível individual de análise do GI. Entretanto, tal como indivíduos usam o GI para influenciar as percepções que outros têm deles, os representantes e porta-vozes das organizações também usam o GI em um esforço para influenciar o modo como outros veem a organização como um todo.

O Gerenciamento de Impressões Organizacional (GIO) pode ser definido como qualquer ação que é intencionalmente planejada e realizada para influenciar as percepções de uma audiência sobre a organização (Bolino, Kacmar, Turnley \& Gilstrap, 2008). Neste trabalho assume-se que as organizações, personificadas pelos seus gestores, podem usar táticas de GIO para criar uma imagem organizacional aos olhos de uma variedade de constituintes.

A taxonomia mais frequentemente citada de táticas de GIO foi desenvolvida por Mohamed, Gardner e Paolillo (1999). Traçado com base na discussão das táticas de GI no nível individual, o trabalho de Mohamed, Gardner e Paolillo (1999) sugere que as táticas de GIO podem ser caracterizadas, usando uma matriz $2 \mathrm{X} 2$, como diretas ou indiretas e como 
assertivas ou defensivas. Táticas diretas envolvem técnicas para apresentar informações sobre as características da organização, suas realizações ou capacidades.

Em contraste, as táticas indiretas buscam gerenciar informações sobre atividades ou outras instituições com as quais a organização está associada. Táticas assertivas são proativas e buscam melhorar a imagem organizacional de algum modo em particular. Em contraste, as táticas defensivas são reativas por natureza e são adotadas em resposta a situações que ameaçam prejudicar a organização de alguma maneira (Bolino, Kacmar, Turnley \& Gilstrap, 2008).

Ginzel, Kramer e Sutton (2004) desenvolveram um modelo de três estágios de GIO baseado no papel desempenhado pela audiência. De acordo com esse modelo, no primeiro estágio os gestores de alto escalão (representantes da organização) tentam criar uma impressão que melhore ou proteja a imagem organizacional.

No estágio dois, os stakeholders reagem aos relatos, às vezes aceitando-os, às vezes desafiando a sua adequação e demandando esclarecimentos e, às vezes rejeitando-os completamente. Então, no terceiro estágio, os gestores buscam negociar um entendimento por meio da resolução das discrepâncias entre o modo como os stakeholders percebem a organização e o modo pelo qual a organização quer ser percebida (Bolino, Kacmar, Turnley \& Gilstrap, 2008).

Ginzel, Kramer e Sutton (2004) abordaram o GIO como um processo de influência recíproca no qual a presença da audiência da organização afeta tanto as tentativas iniciais para explicar as ações e o desempenho organizacional, como também as tentativas subsequentes para resolver conflitos interpretativos.

Ao conceituar o GIO como um processo interativo envolvendo os atores organizacionais (gestores de alto escalão) e os alvos de suas tentativas de influência (os membros da audiência organizacional), estabelece-se a semelhança entre o GIO e o processo de sense-making. Um fator-chave desse processo recíproco é que enquanto os relatos oferecidos pelos gestores são algumas vezes consistentes com a interpretação gerada pelos membros das audiências da organização, em outros momentos, essas interpretações são conflitantes (Ginzel, Kramer \& Sutton, 2004).

A abordagem de Ginzel, Kramer e Sutton (2004) vê o GIO como um processo de negociação. São elementos do modelo de GIO como processo de negociação: 1) o evento precipitador; 2) os gestores de alto escalão da organização; 3) os membros das várias audiências da organização; e 4) os relatos dos gestores de alto escalão. 
Os membros das audiências (stakeholders) são um elemento crítico do processo gerenciamento de impressões. Não apenas a definição da situação da audiência influência como ela reage ao comportamento do ator (gestor de alto escalão), mas também as características da audiência influenciam a definição da situação dos atores (Carter, 2006).

Audiência organizacional inclui os parceiros que proveem os recursos para a organização ou que dela dependem para obter recursos. São grupos que conferem ou diminuem a legitimidade da organização. As audiências podem variar ao longo de um número de dimensões, tais como poder, acesso a informação, natureza da relação com a organização, grau de dependência etc.

Aqui a distinção será feita entre audiências simpatizantes e audiências antagônicas. Audiências simpatizantes são aquelas são aquelas cujas interpretações do evento são consistentes com as informações públicas dos gestores de alto escalão. Por outro lado, audiências antagônicas são aquelas cujas interpretações vão de encontro aos relatos dos gestores (Ginzel, Kramer \& Sutton, 2004).

Ginzel, Kramer e Sutton (2004) desenvolveram um modelo de três estágios de GIO baseado no papel desempenhado pela audiência. O processo de GI é dividido em três fases, as quais descrevem as suas interações dinâmicas.

$\mathrm{Na}$ primeira fase, os gestores de alto escalão geram um relato planejado tanto para melhorar quanto proteger a sua imagem. Aqui o processo de GI envolve reconhecer que um evento que ocorreu (ou que se espera que ocorra) tem o potencial de prejudicar ou contribuir para a imagem desejada da organização. A associação da imagem dos gerentes de alto escalão a um evento é moldada pelas características do evento em si e pelas várias audiências, simpatizantes ou antagônicas, pelas quais os gestores se sentem responsáveis. Os gestores usualmente reconhecem que não podem impor suas próprias interpretações às audiências a menos que essa interpretação seja percebida como aceitável por elas.

Com esse conhecimento, os gestores podem se engajar em ações que tentam prever como diferentes audiências reagirão a seus relatos. Os gestores de alto escalão usam relatos tanto para sustentar a imagem positiva da organização, quando uma oportunidade de melhoria na identidade surge, quanto para minimizar a culpa ou o estigma, quando eventos que ameaçam a identidade acontecem (Ginzel, Kramer \& Sutton, 2004).

$\mathrm{Na}$ segunda fase os membros da audiência organizacional reagem aos relatos. Caso os gestores e a audiência organizacional concordem sobre a interpretação do evento, então nenhuma discrepância existirá entre suas percepções e não existirá conflito interpretativo. Frequentemente, entretanto, os membros da audiência questionam o relato inicial de um 
evento. Membros mais céticos da audiência podem pôr em dúvida a adequação do relato ou demandar esclarecimentos sobre questões não explicadas.

À medida que questionam ou rejeitam os relatos, as audiências podem trazer à tona interpretações conflitantes. Tais interpretações podem colocar os gestores e a organização sob um olhar menos lisonjeiro do que os relatos iniciais dos gestores. O resultado dessas ações é que os gestores de alto escalão se tornam conscientes de que seus relatos estão em conflito com aquela audiência ou com todas as audiências organizacionais, levando a um estado de conflito interpretativo (Ginzel, Kramer \& Sutton, 2004).

Vale destacar que a influência da audiência depende de três fatores principais que, considerados individualmente ou em conjunto, podem afetar a influência de uma audiência sobre o ator: 1) $\mathrm{O}$ número de pessoas na audiência - na medida em que aumenta o número de pessoas em uma audiência, aumenta o impacto da audiência; 2) A proximidade da audiência - refere-se tanto a proximidade física quanto a intimidade entre uma audiência e um indivíduo; e 3) a força (ou status) dos membros da audiência - a força de uma audiência pode ser definida como sendo o poder, o status, ou os recursos (Deaux \& Wrightsman, 1988).

$\mathrm{Na}$ terceira fase ocorrem as tentativas de negociar a resolução do conflito. Conflitos interpretativos indicam um hiato entre o que se espera que os gerentes de alto escalão da organização façam e o que eles realmente fizeram, pois é esperado que esses gestores mantenham o controle sobre suas organizações; inclusive sobre o aprovisionamento das interpretações racionais e interpretações de eventos que são persuasivas para as audiências organizacionais. Quando as interpretações oferecidas pelos gestores de alto escalão entram em conflito com aquelas geradas pelas audiências, ambos engajam-se em um processo que se assemelha a negociação referente à interpretação apropriada dada a um evento.

Uma das dificuldades com as quais os gestores de alto escalão se deparam quando tentam produzir informes aceitáveis e convincentes é a existência de múltiplas audiências pelas as quais eles se sentem responsáveis e as quais devem satisfazer. A presença de múltiplas audiências eleva a complexidade do processo de GIO e contribui para o potencial de conflito interpretativo (Ginzel, Kramer \& Sutton, 2004).

Outra questão que merece atenção é a complexidade informacional. Na medida em que o número de audiências aumenta, existe a probabilidade de um aumento no número de questões em jogo que são percebidas pelos gestores de alto escalão. Quanto mais diversa a audiência e mais heterogêneas suas expectativas, mais complexas se torna a tarefa enfrentada pelos gestores de tentar processar, interpretar e agregar informações e gerar um relato. 
O problema da geração de relatos torna-se consideravelmente mais complicado em contextos de múltiplas audiências, porque relatos dirigidos a uma parte e que buscam produzir um efeito (GI primário) podem produzir consequências bem diferentes em outra audiência (GI secundário).

Os gestores de alto escalão precisam se preocupar não apenas com os efeitos diretos de seus comportamentos sobre uma audiência em particular com a qual eles venham a interagir em algum momento, mas também com os efeitos colaterais de seus comportamentos com outros com os quais eles possam vir a lidar subsequentemente ou simultaneamente (Ginzel, Kramer \& Sutton, 2004).

Tendo sido feitas as considerações sobre o gerenciamento de impressões organizacional, discute-se a seguir o processo de framing.

\subsection{O processo de framing}

A ideia central do framing é a contextualização. O framing situa a informação dentro de um contexto e estabelece "quadros de referência" de tal forma que as pessoas possam avaliar as informações, compreender os seus significados e escolher as suas ações, caso seja apropriado. No processo de framing, a mensagem deve ser imbuída de sinais, "dicas", suficientes para que as pessoas possam dar sentido à mensagem e para que ela seja persuasiva, em outras palavras, para que tenha influência sobre a predisposição das pessoas ou sobre o comportamento manifesto (Hallahan, 1999).

Segundo Marc e Picard (2000) o frame (quadro) designa as estruturas espaciais e temporais onde se inscrevem as interações. Os autores salientam que o quadro espaçotemporal não é simplesmente o meio ambiente, ou uma espécie de "pano de fundo", o qual exerceria efeitos relativamente neutros, mas sim, sendo estruturado pela cultura, apresenta efeitos estruturantes sobre as relações sociais (Hallahan, 1999).

O fenômeno de framing ocorre em diferentes níveis de análise, intrapessoal, interpessoal, grupal, organizacional, interorganizacional e societal (Hallahan, 1999). Neste trabalho a atenção recai sobre o discurso organizacional e a ação dos gestores, entendendose o discurso como um "conjunto de afirmações, conceitos, termos, expressões que constituem o modo de falar ou escrever sobre uma questão em particular, assim 
enquadrando a maneira como as pessoas compreendem e agem em relação a aquela questão" (Watson, 1994 apud Fletcher, 2003, p. 128).

Fairhurst e Sarr (1996) consideram os líderes como "gestores dos significados" de seus mundos e introduzem o conceito da "habilidade de framing": a qualidade da comunicação que motiva outros a aceitarem um significado no lugar de outro. A visão de Fairhurst e Sarr (1996) corrobora a ideia de Smircich e Morgan (1982), sobre a liderança como um processo de gerenciamento de significados, no qual os líderes buscam enquadrar e mudar situações com base em suas ações.

A habilidade de enquadrar (framing) é a ferramenta essencial da gestão de significados; característica fundamental da liderança e dos líderes segundo Smircich e Morgan (1982) e Fairhurst e Sarr (1996). Com base no exposto acima, considera-se neste trabalho que os gestores de alto escalão desempenham fundamentalmente o papel de líderes e exercem a liderança nas organizações, sendo, dessa forma, gestores de significados aos quais buscam influenciar a interpretação da realidade de outros por meio de framing.

Um quadro pode ser definido como uma qualidade de comunicação que leva as outras pessoas a aceitarem um significado no lugar de outro. Dessa forma, os quadros moldam a perspectiva geral sobre a qual as informações são apresentadas e interpretadas. Goffman (1974) define um frame como um esquema de interpretação que provê um contexto para o entendimento da informação e capacita os indivíduos a localizá-la, percebê-la, identificá-la e rotulá-la. Vários processos envolvidos no framing foram identificados por Goffman (1974): a focalização, que se refere a trazer para o foco aspectos particulares da vida cotidiana pela recriação de interações anteriores; a ancoragem, a consolidação de ideias em quadros de significados mais profundos; e a fabricação, refere-se ao resgate de certas dimensões de uma experiência de tão forma que elas se tornem salientes em uma situação de interação.

Segundo Entman (1993) os quadros estão em, ao menos, quatro locais no processo de comunicação: o comunicador, o texto, o receptor e a cultura. Os comunicadores (ou framers) fazem julgamentos conscientes ou inconscientes de framing ao decidir o que dizer (ou como agir, argumenta-se), guiados por quadros (ou esquemas) que organizam seus sistemas de crenças. 
A comunicação contém quadros, os quais são manifestos pela presença ou ausência de determinadas palavras-chave, frases feitas, imagens estereotipadas, fontes de informação, sentenças etc., que fornecem reforços, tematicamente agrupados, de fatos ou julgamentos. Salienta-se que os quadros (modelos mentais ou esquemas) que guiam o pensamento e as conclusões do receptor podem, ou não, refletir os quadros na comunicação e a intenção de framing do comunicador (Entman, 1993).

Determinar o significado de um assunto (questão ou situação) é dar a ele sentido, é julgar a sua natureza e a sua significação. Manter o enquadramento de um assunto é escolher um significado em particular (ou conjunto de significados) no lugar de outro. Ao compartilhar os quadros com outras pessoas (o processo de framing), o indivíduo está gerenciando o significado, na medida em que ele afirma que suas interpretações sobre determinado objeto de atenção devem ser tomadas como reais no lugar de outras possíveis interpretações (Fairhurst \& Sarr, 1996).

Conforme Entman (1993) os quadros desempenham primordialmente quatro funções: 1) os quadros definem os problemas - determinam o que um agente causal está fazendo e com que custos e benefícios, usualmente medidos em termos de valores culturais compartilhados; 2) os quadros diagnosticam causas - identificam as forças que criam o problema; 3) os quadros fazem julgamentos morais - avaliam os agentes causais e seus efeitos; e 4) os quadros sugerem medidas - oferecem e justificam tratamentos para os problemas e predizem os seus prováveis efeitos.

Chama-se a atenção para o fato de que uma única mensagem em um processo de comunicação pode conter uma ou mais das quatro funções do framing, porém, muitas mensagens podem não desempenhar nenhuma das quatro funções e, ainda, uma mensagem pode não necessariamente incluir todas as quatro funções (Entman, 1993).

Reese (1982) afirma que os quadros são princípios organizadores, socialmente compartilhados e persistentes no decorrer do tempo, que trabalham simbolicamente para significativamente estruturar o mundo social. É necessário se ter em mente que apesar da característica da persistência (relativa estabilidade), os quadros não são estruturas permanentes e imutáveis; eles estão em constante processo de mudança, o que pode fazer com que alguns deixem de ser compartilhados entre algumas pessoas no decorrer do tempo, sendo o inverso também verdadeiro. 
O processo de framing essencialmente envolve dois aspectos: seleção e saliência. Os quadros, no processo de framing, destacam algumas partes da informação sobre um assunto que é o objeto da comunicação, dessa forma elevando sua saliência (Entman, 1993). O termo "saliência" refere-se, de acordo com Entman (1993, p. 53), a "fazer um pedaço de informação mais noticiável, significativo ou memorável para as audiências. Um aumento na saliência aumenta a probabilidade de que o receptor perceberá a informação, discernirá seu significado e, assim, a processará e a armazenará em sua memória”.

A atividade de enquadrar envolve selecionar alguns aspectos de uma realidade percebida e torná-los mais salientes em uma comunicação, de tal modo a promover uma determinada definição de um problema, uma interpretação causal, uma avaliação moral e/ou recomendações de tratamento para o assunto descrito. Dessa forma, usualmente os quadros diagnosticam, avaliam e prescrevem (Entman, 1993).

Entretanto, os quadros exercem influência não apenas pelo que eles salientam, mas também pelo que eles deixam de lado. O framing em todos os quatros locais (comunicador, texto, receptor e cultura) inclui funções similares: seleção e destaque; além do uso dos elementos destacados para construir um argumento sobre problemas e suas causas, avaliações e/ou soluções (Entman, 1993).

O processo de framing é uma atividade crítica na construção social da realidade, porque ele ajuda a moldar as perspectivas pelas quais as pessoas veem o mundo ao seu redor. Sob uma abordagem metafórica, o framing pode ser mais bem entendido como uma "janela" ou "moldura" estabelecida ao redor da informação, a qual delimita o assunto em questão e, assim, foca a atenção em elementos-chaves dentro do quadro. Desse modo, o framing envolve processos de inclusão, exclusão e ênfase (Hallahan, 1999).

No framing, percebe-se a importância da ação dos gestores de alto escalão (como framers) - gestores de significados Smircich e Morgan (1982) e Fairhurst e Sarr (1996) ao desempenharem os papéis gerencias (Mintzberg, 1973), no sentido de obter a legitimidade para a organização diante de seus stakeholders.

Como propriedade de uma mensagem, um quadro limita ou define o significado da mensagem por meio da moldagem das inferências que os indivíduos fazem acerca da mensagem. Os quadros refletem os julgamentos feitos pelos criadores das mensagens (ou framers). Alguns quadros representam as valências alternativas das informações (colocando as informações sob um enfoque positivo ou negativo - framing de valência); 
outros quadros envolvem simplesmente o estilo linguístico dos termos (framing semântico).

A mais complexa forma de framing é o storytelling (framing de storytelling). $\mathrm{O}$ framing de storytelling envolve: a) selecionar temas-chave ou ideias que são o foco da mensagem e b) incorporar uma variedade de storytelling ou técnicas de narrativa que suportam o tema (Hallahan, 1999).

Ao interagir com outros, segundo Fletcher (2003), os indivíduos estão utilizando recursos linguísticos (conceitos, ideias, visões, rótulos) para expressar e dar voz a aspectos da vida organizacional. Desse modo, a linguagem é performativa - e ajuda a construir as experiências dos indivíduos e a prover os significados por meio dos quais os indivíduos moldam sua identidade e percebem oportunidades de autoapresentação.

Os indivíduos, ao falar e interagir com outros, criam os significados das coisas que estão ao seu redor, pois a linguagem molda e dá perspectiva à "realidade". Entretanto, o que é dito pelas pessoas varia de acordo com as audiências para quais elas estão se dirigindo e com o contexto social, político ou cultural no qual elas estão situadas (Fletcher, 2003).

No sentido de engajar-se em um processo de framing determinada a situação para outros, os indivíduos devem primeiramente enquadrar a situação para si mesmos. Para enquadrar a realidade internamente (cognitivamente), as pessoas baseiam-se em seus modelos mentais (Fairhurst \& Sarr, 1996). Um modelo mental é um recurso que identifica as dimensões ao longo das quais as experiências serão julgadas e subsequentemente comunicadas aos outros.

É importante para os indivíduos trazer os modelos mentais ao nível consciente, pois caso contrário os modelos podem ser restritivos; tornarem-se pressupostos incorretos acerca do mundo que podem escapar da atenção do indivíduo. Desse modo, sempre que possível, as pessoas devem refletir sobre os seus modelos mentais antes de necessariamente precisar deles (Fairhurst \& Sarr, 1996). Destaca-se que na literatura especializada os frames individuais (cognitivos) são às vezes equiparados a modelos mentais e esquemas mentais.

O quadro determina se a maioria das pessoas perceberá um assunto e como elas compreenderão e se lembrarão dele, além de como as pessoas avaliarão e escolherão agir em relação a ele. A noção de framing significa então que o quadro, no processo de 
comunicação, tem um efeito semelhante sobre uma grande porção da audiência receptora, embora exista pouca probabilidade de que o quadro tenha um efeito universal sobre todos os seus membros da audiência (Entman, 1993).

Observa-se que a teoria de framing é bastante adotada nos estudos sobre comunicação de massa. Hallahan (1999) chama a atenção para o fato de que na área de relações públicas, o processo de framing pode ser examinado a partir de uma variedade de modelos, incluindo a perspectiva de sistemas, a perspectiva crítica e a perspectiva da retórica. Salienta-se, que dentre essas perspectivas, este trabalho segue uma orientação da perspectiva da retórica, pois se acredita que está seja a perspectiva mais adequada ao fenômeno em questão.

A perspectiva da retórica foca-se, conforme Hallahan (1999) em como são construídos mensagens e significados planejados para influenciar públicos-chave importantes para uma organização. O framing que é conceitualmente conectado ao processo psicológico subjacente que as pessoas usam para examinar as informações, para fazer julgamentos e para esboçar inferências acerca do mundo a seu redor, soma-se a abordagem retórica, a qual foca-se em como as mensagens são criadas (Hallahan, 1999). Esta assertiva parece corroborar a escolha da perspectiva da retórica como orientadora deste trabalho.

O framing atua criando uma tendência, uma convergência, no processamento cognitivo de informações pelos indivíduos. Ao menos dois mecanismos que explicam esse processo são observados na literatura especializada. O primeiro sugere que o framing opera provendo dicas contextuais que guiam a tomada de decisão e as inferências formadas pela audiência. O segundo mecanismo por meio do qual o framing opera é o priming.

O conhecimento é organizado na memória humana em estruturas cognitivas ou esquemas, os quais operam como limitações sobre a disposição e a interpretação de situações e eventos. Os esquemas também têm sido conceituados na literatura especializada como categorias (estruturas hierárquicas), como protótipos (representações idealizadas de objetos dentro de uma classe particular) e como scripts (cenários esperados para determinados eventos) (Hallahan, 1999).

A ênfase do framing no contexto de aprovisionamento no qual a informação é apresentada e processada permite que framing seja aplicado através de um amplo espectro de situações de comunicação (Hallahan, 1999). Com base em uma revisão de literatura, Hallahan (1999) propôs uma tipologia de sete modelos de framing, a qual envolve o 
enquadramento da situação, dos atributos, das escolhas, das ações, das questões, das responsabilidades e das notícias (Quadro 1).

Quadro 1 - Tipologia dos sete modelos de framing.

\begin{tabular}{|c|c|}
\hline $\begin{array}{l}\text { O QUEÉ } \\
\text { ENQUADRADO }\end{array}$ & DESCRIÇÃO \\
\hline Situações & $\begin{array}{l}\text { Relações entre indivíduos em situações encontradas no dia a dia e na } \\
\text { literatura. O framing de situações provê estruturas para examinar a } \\
\text { comunicação. Aplica-se a análise do discurso, a negociação e outras } \\
\text { interações. }\end{array}$ \\
\hline Atributos & $\begin{array}{l}\text { Características de objetos e pessoas são acentuadas, enquanto outras são } \\
\text { ignoradas, assim influenciando o processamento de informações em } \\
\text { termos de atributos focais. }\end{array}$ \\
\hline Escolhas & $\begin{array}{l}\text { Apres entar alternativas de decisões tanto em termos neg ativos (perdas), } \\
\text { quanto positivos (ganhos) pode influenciar as escolhas em situações } \\
\text { envolvendo incerteza. As pessoas as sumirão maiores riscos para evitar } \\
\text { perdas do que para obter ganhos. }\end{array}$ \\
\hline Ações & $\begin{array}{l}\text { Em contextos de persuasão, a probabilidade de que uma pessoa agirá } \\
\text { para atingir o objetivo desejado é influenciada pela forma como as } \\
\text { alternativas são apresentadas - em termos positivos ou negativos. }\end{array}$ \\
\hline Questões & $\begin{array}{l}\text { Problemas e dis putas sociais podem ser explicados em termos } \\
\text { alternativos pelas diferentes partes que competem por suas definições de } \\
\text { um problema ou situação que prevaleçam. }\end{array}$ \\
\hline Responsabilidade & $\begin{array}{l}\text { Indivíduos tendem a atribuir as causas dos eventos a fatores internos ou } \\
\text { externos, baseados em níveis de estabilidade e controle. As pessoas } \\
\text { descrevem seus papéis nos eventos de forma consistente com suas } \\
\text { autoimagens de modo a maximizar os benefícios e a minimizar a } \\
\text { culpabilidade. As pessoas atribuem causas as ações dos indivíduos ao } \\
\text { invés de aos problemas sistêmicos da sociedade. }\end{array}$ \\
\hline Notícias & $\begin{array}{l}\text { Os relatos da mídia usam temas familiares e que sejam culturalmente } \\
\text { ressonantes para transmitir informações sobre os eventos. As fontes } \\
\text { disputam no processo de framing. }\end{array}$ \\
\hline
\end{tabular}

Fonte: Adaptado de Hallahan (1999). 
O viés antropológico e sociológico do uso de framing para descrever como a realidade é construída por meio da linguagem e pela estrutura das interações entre as pessoas pode ser denominado como framing de situações (Hallahan, 1999). Goffman descreve o framing de situações como "a definição da situação [...] construída com base na concordância com os princípios da organização que governam os eventos - ao menos os sociais - e nossos envolvimentos subjetivos com eles" (Goffman, 1974, p. 10).

Hallahan (1999) destaca o framing situacional como o processo por meio do qual os gestores de todos os níveis tentam impor suas visões da realidade em determinadas situações. A situação na qual os atores sociais se encontram deve ser consistente com as suas expectativas.

As oportunidades de comunicação devem ser organizadas (ou enquadradas) de modo a irem ao encontro das expectativas dos participantes. Não satisfazer as expectativas relacionadas às organizações ritualísticas ou a atmosfera simbólica, pode redefinir o evento (situação) e levar os participantes a inferências que sejam justamente o oposto do que foi intencionado pelos "responsáveis pelo evento" (framers) (Hallahan, 1999).

Uma segunda e distinta forma de framing envolve o framing de atributos - o qual se refere à caracterização de objetos, eventos e pessoas. Quando usado nesse contexto, um framing semântico é utilizado para direcionar o foco sobre determinados atributos que podem ser favorecedores ou derrogatórios e, então, ser vantajosos ou desvantajosos para o framer da mensagem na comunicação persuasiva (Hallahan, 1999).

Outra importante forma de framing pode ser observada quando os indivíduos devem fazer uma escolha entre opções independentes em situações nas quais algum nível de incerteza ou risco está presente - framing de escolhas (Hallahan, 1999).

O framing de ações está relacionado, conforme Hallahan (1999), à melhor forma de descrever a ação (ou curso de ações) que deve ser tomada pelo indivíduo para atingir um objetivo desejado.

O processo de framing como um modo de interpretar a realidade social vem recebendo atenção entre sociólogos e outros acadêmicos. Esta abordagem é denominada como framing de questões. Uma "questão" é uma disputa entre duas ou mais partes, usualmente sobre a alocação de recursos ou sobre o tratamento ou descrição de grupos na sociedade. As questões frequentemente resultam de extensas discussões públicas e frequentemente 
requerem a resolução em fóruns de política pública, tais como o legislativo ou os tribunais (Hallahan, 1999).

A maioria das questões e problemas sociais acarreta indagações sobre causa e responsabilidade - quem deveria receber os créditos ou ser culpado pelos eventos. A atribuição de um evento a fatores pessoais ou ambientais determina a extensão na qual um indivíduo é considerado responsável. Entretanto, a atribuição de responsabilidade nem sempre reflete precisamente os fatos objetivos de uma situação e pode ser distorcida com base na forma como os eventos são descritos, em outras palavras, como o evento que foi enquadrado. Isto aponta para outro tipo relevante de framing, o qual é denominado de framing de responsabilidade (Hallahan, 1999).

Argumenta-se que framing de responsabilidade, ou seja, a aceitação ou negação de ser responsável por eventos, tem implicações significativas para a área de gestão, especialmente no que se trata dos processos de legitimação.

O modelo final de framing, proposto por Hallahan (1999), trata de como as notícias são descritas ou enquadradas pela mídia em um esforço de explicar ideias complexas e abstratas em termos familiares e culturalmente ressonantes - a este modelo é dado o nome de framing de notícias. Ao framing de notícias podem ser incorporadas muitas das noções de framing discutidas anteriormente neste trabalho. Quase invariavelmente o framing de notícias corresponde ao enquadramento ou entendimento esquemático do evento por pelo menos alguns grupos (Hallahan, 1999).

Ao enquadrar este artigo aos sete modelos de framing de Hallahan (1999), selecionase e enfatiza-se uma visão do processo de framing. Entretanto, é importante deixar claro que os autores deste trabalho, ao excluir outras visões possíveis sobre o fenômeno, buscaram organizar as informações sobre o construto no sentido de criar um quadro de referência que pudesse ser compartilhado; de modo a fornecer um contexto no qual os conceitos a serem trabalhados na construção do modelo analítico tivessem significado.

Não se pretendeu uma revisão de literatura exaustiva sobre o tema, nem determinar o arcabouço teórico elaborado como uma visão paradigmática para o estudo e interpretação do fenômeno de framing.

Tendo em mente que "no processo de organizar as comunicações entre uma organização e seus públicos-chave, uma preocupação principal deve ser a estruturação dos encontros de modo que eles sejam favoravelmente recebidos e reforcem a intenção da 
comunicação para todas as partes (audiências)" (Hallahan, 1999. p. 224), é apresentado a seguir a proposição do modelo analítico.

Tal proposta busca dar suporte teórico ao argumento de que os gestores de alto escalão ao se relacionarem com os stakeholders engajam-se em processos de gerenciamento de impressões visando enquadrar (framing) as percepções e as interpretações das audiências organizacionais à visão de realidade mais propícia a criação da imagem e da reputação que levem a obtenção da legitimidade da organização em seu ambiente social.

\section{PROPOSTA DE MODELO ANALÍTICO}

Por sua capacidade de moldar as perspectivas pelas quais as pessoas veem o mundo o processo de framing é considerado uma atividade crucial na construção social da realidade (Hallahan, 1999) e, argumenta-se, uma atividade gerencial fundamental para a obtenção da legitimidade da organização em seu ambiente social.

Como as organizações concorrem entre si pela legitimidade e aceitação de seus stakeholders, a capacidade e a habilidade de influenciar as definições da realidade (framing) dos membros da sociedade dos quais elas dependem, com o objetivo de fazer com que suas ações sejam percebidas como corretas e apropriadas e, dessa forma, obter a legitimidade, deve ser visto como um imperativo organizacional e um aspecto fundamental para a sobrevivência e desenvolvimento da organização.

O modelo apresentado por Mendonça e Amantino-de-Andrade (2003) buscou explicar como as organizações por intermédio do gerenciamento de impressões buscam criar imagens que thes proporcionam legitimação no ambiente social. Segundo o modelo, a conformidade às regras e requerimentos dos stakeholders não é suficiente para que as organizações obtenham a aceitação de seus constituintes, pois é necessário comunicar, tornar perceptível, a conformidade.

Apesar de trazer uma inovação ao integrar as teorias de gerenciamento de impressões e de comunicação corporativa para explicar, sob a ótica institucional, como as organizações agem para obter legitimidade, o Modelo do Processo de Legitimidade por meio do uso do Gerenciamento de Impressões Organizacional de Mendonça e Amantino-de-Andrade (2003) deixou de considerar importantes aspectos do fenômeno. Dessa forma, apesar de não estar incorreto, o referido modelo carece de maior poder explicativo. 
Propõe-se aqui uma versão expandida do modelo de Mendonça e Amantino-deAndrade (2003), o qual incorpora o processo de framing e a reputação organizacional, denominado "Modelo do processo de legitimação organizacional por meio do gerenciamento de impressões organizacional e do framing dos stakeholders" (Figura 1).

Figura 1 - Modelo do processo de legitimação organizacional por meio do gerenciamento de impressões organizacional e do framing dos stakeholders.



Fonte: Elaborado pelos autores, com base em Ginzel, Kramer \& Sutton (2004); Hallahan (1999); Entman (1993); Smircich e Morgan (1982).

As organizações são vistas no modelo como atores sociais que são representados, internamente e externamente, por seus gestores de alto escalão, os quais ao representar a organização, ao manter a ligação entre a organização e suas audiências, ao controlar o fluxo de informações-chave, ao buscar solucionar problemas ou neutralizar ameaças à organização e ao atuar como negociadores em nome da organização, constroem ou ajudam a construir os relacionamentos com os stakeholders.

O processo de busca de legitimação no ambiente e de comunicação com os stakeholders é influenciado pela cultura e pela identidade da organização. Não está no escopo deste trabalho discutir a relação entre cultura e identidade organizacional. Entretanto, defende-se que a identidade organizacional - a forma como os membros internos realmente 
pensam as características da organização (Brown, Dacin \& Pratt, 2006) - é determinada pela cultura organizacional.

Os gestores de alto escalão, como gestores de significados (Smircich \& Morgan, 1982; Fairhurst \& Sarr, 1996), diante de um evento precipitador engajam-se em esforços para criar, manter ou alterar a imagem e/ou a reputação da organização diante da audiência organizacional por meio de processos de gerenciamento de impressões organizacional.

Conforme os objetivos de comunicação, os quais afetarão as escolhas das estratégias e táticas do GIO, os gestores estabelecerão um processo de comunicação com os stakeholderschave. Para tanto serão selecionadas, conforme Mendonça e Amantino-de-Andrade (2003), as ferramentas de comunicação corporativas mais adequadas à situação e ao tipo de interação (face a face ou mediada). Em processos de interação face a face, os gestores devem levar em consideração fatores específicos do cenário ambiental (Gardner \& Martinko, 1988), além de aspectos relacionados à comunicação não verbal, por vezes não planejada.

Os gestores engajados em atividades de GIO, como estrategistas de framing (framers), buscam então selecionar e salientar aspectos da realidade, de maneira a propiciar que a definição da situação da audiência (Gardner \& Martinko, 1988) e a sua interpretação do assunto suscitado pelo evento precipitador sejam favoráveis à organização; assim, buscando excluir interpretações alternativas, que poderiam ser desfavoráveis.

Nesse contexto, os gestores buscam determinar e implementar maneiras de apresentar a situação, os atributos, as escolhas, as ações, as questões e as responsabilidades associadas de forma favorável diante de audiências organizacionais que são o alvo da comunicação, as quais podem ser simpatizantes ou antagônicas a interpretação informada nos relatos dos gestores.

Assumindo que os gestores tomaram todas as decisões corretas até o momento de transmitir a mensagem a suas audiências, ainda há a possibilidade de que as impressões formadas pelas audiências não sejam aquelas pretendidas pelos gestores. As impressões secundárias, que podem ser totalmente o inverso do que se buscava obter, são uma ameaça ao processo de legitimação, pois podem prejudicar a imagem e a reputação da organização.

Caso os esforços da organização tenham sido bem-sucedidos e ela tenha conseguido a formação de impressões positivas entre os membros das audiências, acredita-se que essa impressão contribua para que a imagem interpretada pelos stakeholders seja positiva. Nesse caso, argumenta-se com base no modelo de Mendonça e Amantino-de-Andrade (2003) e na literatura pesquisada, que a organização terá grandes probabilidades de obter a legitimidade por parte de seus constituintes e conseguir os recursos de que necessita de seu ambiente. 
O status de legitimidade, de organização que atende aos requerimentos das normas sociais, impacta positivamente na construção e manutenção de uma boa reputação organizacional. Em um processo de mão dupla, a boa reputação organizacional contribuirá para a obtenção e/ou manutenção da legitimidade da organização diante de suas audiências; assim, como a falta de legitimidade prejudica a imagem e a reputação organizacional.

Apesar dos esforços dos gestores para enquadrar as percepções dos stakeholders, impressões negativas e interpretações discrepantes por parte da audiência, podem gerar conflitos interpretativos e fazer com que a organização não consiga obter o status de legitimidade.

Nesses casos, argumenta-se que os gestores de alto escalão, percebendo o conflito interpretativo, buscarão negociar os significados e as interpretações em um novo processo de framing, o qual poderá solucionar o conflito, fazendo com que os gestores e as audiênciaschaves compartilhem quadros de referências em comum e levando a obtenção da legitimidade organizacional; ou, por outro lado, poderá não surtir o efeito planejado, o que não eliminaria o conflito interpretativo e provocaria a não obtenção da legitimidade ou ainda a perda da legitimidade já conquistada pela organização caso o evento precipitador se caracterize como um momento de crise organizacional.

\section{CONSIDERAÇÕES FINAIS}

Acredita-se que o modelo apresentado na Figura 1 foi capaz de ilustrar a argumentação teórica para a proposição de que os gestores de alto escalão empreendem, ao se relacionarem com os stakeholders, processos de gerenciamento de impressões organizacional visando enquadrar (framing) as percepções e as interpretações das audiências organizacionais à visão de realidade mais propícia a criação da imagem e da reputação que levem a obtenção da legitimidade da organização em seu ambiente social. A proposição deste artigo e a elaboração do modelo explicativo tiveram como objetivo responder à pergunta de pesquisa: como os gestores de alto escalão, no processo de comunicação com os stakeholders, tentam influenciar as interpretações das audiências em busca de legitimidade para a organização? Pergunta essa a qual se considera teoricamente respondida. $\mathrm{O}$ debate sobre o modelo nos leva a crer que os gestores de alto escalão, percebendo o conflito interpretativo, podem negociar os significados e as interpretações em um novo processo de framing, o qual poderá solucionar o 
conflito, fazendo com que os gestores e as audiências-chaves compartilhem quadros de referências em comum e levando à obtenção da legitimidade organizacional

Não se tem a pretensão de esgotar a discussão sobre o tema, muito menos de dar conta de todos os aspectos envolvidos em um fenômeno tão complexo como o discutido neste trabalho. Dessa forma, algumas limitações e sugestões para futuros estudos são realizadas a seguir.

Fatores intrapsíquicos e sociais salientados nas teorias de GI, como nos modelos de Gardner e Martinko (1988) e Leary e Kowalski (1990), por exemplo, não foram considerados no modelo proposto. Avaliar fatores intrapsíquicos dos gestores e dos membros das audiências, tais como traços de personalidade, status, poder, dentre outros, pode ajudar a melhor compreender o processo de GIO e de framing.

Observa-se, então, que o campo para os estudos sobre o gerenciamento de impressões organizacional, o framing, a imagem, a reputação e a legitimidade é bastante vasto e oferece interessantes desafios e oportunidades para pesquisadores interessados em compreender os fenômenos organizacionais.

Além disso, cumpre destacar que o modelo proposto tem forte aplicação empírica nas organizações, em áreas como comunicação institucional, gestão da imagem e da reputação organizacional, gestão de stakeholders e de crise, dentre outras áreas e possibilidades.

\section{REFERÊNCIAS}

Bolino, M.; Kacmar, K.; Turnley, W. \& Gilstrap, J. (2008). A multi-level review of impression management motives and behaviors. Journal of Management, vol. 34, n. 6, pp. 1080-1109.

Brown, T.; Dacin, P. \& Pratt, M. Whetten, D. (2006). Identity, intended image, construed image, and reputation: an interdisciplinary framework and suggested terminology. Journal of the Academy of Marketing Science, vol. 34. n.2. pp. 99-106.

Carter, S. (2006). The interaction of top management group, stakeholder, and situational factors on certain corporate reputation management activities. Journal of Management Studies, vol. 43, n.5, pp. 145-1176.

Deaux, K. \& Wrightsman, L. (1998). Social psychology (5a ed.). Belmont: Brooks/Cole. 
Entman, R. (1993). Framing: toward clarification of a fractured paradigm. Journal of Communication, vol. 43, n. 4, pp. 51-58.

Fairhurst, G. \& Sarr, R. (1996). The art of framing. San Francisco: Jossey-Bass.

Fletcher, D. (2003). Framing organizational emergence: discourse, identity and relationship. In: Steyaert, C. \& Hjorth, D. (eds.). (2003). News movements in entrepreneurship. MPG books, Bodmin, Cornwall, pp. 125-144.

Freeman, R. E. (1984). Strategic management: a stakeholder approach. Massachusetts: Pitman.

Gardner, W. \& Martinko, M. (1988). Impression management in organization. Journal of Management, vol. 14, pp. 311-338.

Giacalone, R. \& Rosenfeld, P. Impression management in the organization: an overview. In: Giacalone, R. \& Rosenfeld, P. (eds.). (1989). Impression Management in the organization. Lawrence Erlbaum: Hillsdale, New Jersey.

Ginzel, L.; Kramer, R. \& Sutton, R. (2004). Organizational impression management as a reciprocal influence process: the neglected role of the organizational audience. In: Hatch, M. \& Schultz, M. Organizational identity: a reader. Oxford University Press: Oxford, pp. 223-261.

Goffman, E. (1974). Frame analysis. Cambridge, MA: Harvard University Press.

Hallahan, K. (1999). Seven models of framing: implications for public relations. Journal of Public Relations Research, vol. 11. n. 3, pp. 205-242.

Hooghiemstra, R. (2000). Corporate communication and impression management. Journal of Business Ethics, vol 27, pp. 55-68.

Kaplan, S. (2008). Framing contests: strategy making under uncertainty. Organization Science, vol. 19, n. 5, pp. 729-752.

Leary, M. \& Kowalski, R. (1990). Impression management. Psychological Bulletin, vol. 107, n. 1 , pp. 34-47.

Marc, E. \& Picard, D. (2000). La interacción social. Buenos Aires: Ed. Paidos Ibérica. 
Mendonça, J. R. C. \& Amantino-de-Andrade, J. (2002). Teoria institucional e gerenciamento de impressões. II Eneo, 2002, Recife. Anais... Recife: Propad/UFPE/Anpad.

. (2003). Gerenciamento de impressões: em busca de legitimidade organizacional. Revista de Administração de Empresas (RAE), vol. 43, n.1.

Mendonça, J. R. C. \& Fachin, R. (2001). Impressions management, power, and politics: mysteries that surround our vain epistemology: a theoretical exercise. Egos Colloquium, 17, 2001, Lyon. Annals... Sub theme n. 3, Organizational Theatre. Lyon.

; Gonçalves, J. C. S. (2004). Responsabilidade social nas empresas: uma questão de imagem ou de essência? Organizações \& Sociedade, vol. 11, n. 29, pp. 115-130.

Mintzberg, H. (1973). The Nature of Managerial Work. New York: Harper \& Row.

Mohamed, A.; Gardner, W. \& Paolillo, J. (1999). A taxonomy of organizational impression management tactics. Advances in Competiveness Research, vol. 7, n. 1, pp. 108-130.

Reese, S. (1982) Framing public Life: a bridging model for media research. In. Reese, S.; Smircich, L. \& Morgan, G. Leadership: the management of meaning. Journal of Applied Behavioural Science vol.18, n. 3, pp. 257-273.

(1997). Liderança: a administração do sentido. In: Bergamini, C. W. \& Coda, R. Psicodinâmica da vida organizacional: motivação e liderança (2a ed.). São Paulo: Atlas.

Savage, G. T., Nix, T. W., Whitehead, C. J. \& Blair, J. D. (1991). Strategies for assessing and managing organizational stakeholders. Academy of Management Executive, 5(2), 6175 .

Suchman, M. (1995). Managing legitimacy: strategic and institutional approaches. Academy of Management Review, vol. 20, n. 3, pp. 571-610. 